\title{
We choose what we like - Affect as a driver of electricity portfolio choice
}

\section{Working Paper}

\section{Author(s):}

Jobin, Marilou; Siegrist, Michael

Publication date:

2018-11

Permanent link:

https://doi.org/10.3929/ethz-b-000289934

\section{Rights / license:}

Creative Commons Attribution-NonCommercial-NoDerivatives 4.0 International 


\title{
We choose what we like - Affect as a driver of electricity portfolio choice
}

Marilou Jobin $_{\mathrm{a}}{ }^{\text {, }}$, Michael Siegrist $\mathrm{a}$

a ETH Zurich, Institute for Environmental Decisions (IED), Consumer Behavior, Universitaetstrasse 22, 8092 Zurich, Switzerland

*corresponding author, E-mail address: marilou.jobin@hest.ethz.ch, phone number: +41 446338316

\section{Highlights}

- Affect drives the proportion of the energy technologies included in a portfolio.

- Underlying concerns additionally play a role in portfolio preferences.

- $\quad$ Portfolio preferences are not uniform across the Swiss public.

- Policy implementation needs to consider affective reactions and concerns.

\begin{abstract}
Numerous countries are restructuring their electricity systems. Transitioning to electricity systems that are considered acceptable by the public requires that the public's preferences be taken into account. In this study, we investigate the type of energy technology portfolio that people prefer for Switzerland, and why they prefer it, when they are faced with two realistic constraints: (i) the limited domestic potential for the expansion of power plants and (ii) the requirement to not dismantle existing infrastructure. We find that the affect evoked by particular energy technologies is consistently the most important driver of the proportion of those technologies included in an energy portfolio. The regression models for the investigated technologies explain between $14 \%$ and $54 \%$ of the variance, providing strong support for the affect heuristic. We further find that concerns regarding environmental impacts, costs or climate change play an additional role for portfolio preferences. This is reflected in four different clusters we identified for the German-speaking Swiss population who potentially hold opposing views as to what they consider the best electricity mix. For policymakers, our findings suggest that positive affective reactions towards energy technologies are necessary, although concerns must also be considered if the implementation is to be widely accepted.
\end{abstract}

Keywords:

energy mix, portfolio preference, electricity system, energy transition, affect

1 C 2018. This manuscript version is made available under the CC-BY-NC-ND 4.0 license http://creativecommons.org/licenses/by-nc-nd/4.0/

https://doi.org/10.1016/j.enpol.2018.08.027

Accepted 12 August 2018 


\section{Introduction}

Similar to many other countries worldwide, Switzerland is currently in the process of restructuring its energy system. Following the nuclear accident in Fukushima in 2011, a new Swiss energy policy was developed, which includes the phasing-out of nuclear power. The first major hurdle to this new policy has now been overcome, since the new energy law was finally approved in a referendum vote ${ }^{2}$ by the Swiss population in May 2017 (FC, 2017; SFOE, 2017). The second, now impending, step in the process involves implementing the national policy in a way the public accepts. Policymakers therefore need to identify the most desirable and acceptable energy mix for the year 2035, which is a milestone in the Swiss energy transition (SFOE, 2013). Determining people's preferences in terms of energy technologies as well as the factors that drive those preferences can help policymakers with the implementation of the law.

The focus of previous studies has been public acceptance of individual electricity technologies (Greenberg, 2009; Greenberg and Truelove, 2011; Visschers and Siegrist, 2014). Their findings indicate that the public commonly prefers solar and wind power over non-renewable technologies such as coal, natural gas or nuclear power. However, from a technical standpoint, electricity cannot always be provided using a single technology. Rather, there exist certain limitations on the composition of the future electricity mix. One major constraint is the limited potential to increase domestic power production for certain technologies. In Switzerland, for instance, neither solar power (Assouline et al., 2017; Kienast et al., 2017) nor hydropower (SFOE, 2012) can cover the entire domestic electricity demand on their own, which demonstrates their limited technical capacities. Moreover, some of the electricity supply is already ensured through power plants that will still be operational in 2035 . Dismantling this existing infrastructure would be extremely costly. We therefore suggest that it is important to examine the type of energy technology portfolio that the public prefers for power generation, as well as why they prefer it, when faced with two realistic constraints: (i) the limited

\footnotetext{
2 Referendum votes represent a means of direct democracy. Changes to the constitution always require a referendum vote in Switzerland, while changes to the law can be subject to a facultative referendum, under the condition that it has been requested by 50,000 voters or eight cantons within a 100-day period following a parliamentary decision (Stykow, 2007).
} 
domestic potential for the expansion of power plants and (ii) the requirement to not dismantle existing infrastructure.

The present study investigates the portfolio choices associated with energy technologies, with a focus on the type of electricity mix people would prefer to see implemented in the future in order to meet Switzerland's electricity demand. The aim is to examine those factors driving the portfolio choice that have been shown to be associated with the acceptance of the same set of energy technologies. As members of the public might differ with regards to their preferences for energy technologies (Greenberg and Truelove, 2011), a sub-aim of the study is to explore whether the examined sample of individuals exhibit dissimilar preferences in relation to the future electricity mix as well as whether their preferences are compatible with the new energy law.

\subsection{Acceptance vs. portfolio choice}

Acceptance can be, and indeed has been, investigated at the national, community or individual/organisational level. These levels respectively correlate with the object of acceptance, i.e. the type of energy technology, infrastructure project or on-site energy applications (Upham et al., 2015). We focus on the problem scope of technology acceptance at the country level, thereby shedding light on the types of energy technologies that are accepted in various countries. In general, renewable energies are preferred over nuclear power and fossil fuels in both Switzerland (Rudolf et al., 2014; Visschers and Siegrist, 2014) and elsewhere (Ansolabehere and Konisky, 2014; Bronfman et al., 2012; Ertör-Akyazı et al., 2012; Greenberg and Truelove, 2011). However, the way acceptance is operationalised differs across these studies. Some studies measure preferences for an increase or decrease in electricity produced by a certain technology (Ansolabehere and Konisky, 2014; Greenberg, 2009; Greenberg and Truelove, 2011), while others focus on the degree of being in favour of or opposed to local energy systems (Noppers et al., 2014) or the building of new power plants (Sütterlin and Siegrist, 2017). Similarly, acceptance has also been determined as the degree of accepting the expansion of a given energy technology (Peters and Slovic, 1996; Tampakis et al., 2013; Visschers and Siegrist, 2012; Visschers and Siegrist, 2014; Visschers and Wallquist, 2013) or accepting the replacement of existing technologies (Keller et al., 2012). When determining the acceptance of separate energy 
technologies, no trade-offs have to be made between the different energy technologies. Theoretically, an individual can accept the expansion of all energy technologies or be opposed to the building of any new kind of power plant. While these acceptance measures provide us with a generic insight into public acceptance, they fail to deliver insights into preferences for realistic energy portfolios. We contend that it is thus necessary to take into account the requirements and constraints of the electricity system in order to ensure that realistic portfolio preferences are indicated.

Requirements in this regard are most commonly related to the need to expand power generation and therefore current capacities so as to meet the growing electricity demand (Ansolabehere and Konisky, 2014). In the case of Switzerland, the electricity demand for the year 2035 is estimated to increase between $7.1 \%$ and $25.3 \%$ when compared to the year 2000 (SFOE, 2013). The need to construct new power plants is further amplified by the phasing-out of existing nuclear power plants, which currently account for $30-35 \%$ of domestic electricity production (SFOE, 2016). Moreover, constraints derive from the limited potentials ascribed to the expansion of the different types of power plants (SFOE, 2012, 2013). This can be due to potential conflicts with other services (habitat protection, groundwater protection, landscape services, etc.) (Kienast et al., 2017), limited resources, as in the case of biomass (Panos and Kannan, 2016), or limited adequate siting possibilities for solar panels on rooftops (Assouline et al., 2017).

We draw on the literature concerning the development and testing of decision support frameworks in order to elicit public preferences regarding the energy system (change) (Bessette et al., 2014; Bessette et al., 2016; Demski et al., 2017; Mayer et al., 2014; Pidgeon et al., 2014). In contrast to the approach applied in the acceptance literature, here the respondents are asked to generate their preferred portfolios based on a set of different energy technologies or conservation measures. The portfolios are required to meet a certain electricity demand, which is sometimes combined with $\mathrm{CO}_{2}$ reduction targets (Mayer et al., 2014). Further, the amount that a given technology can contribute to a portfolio is constrained, since only a limited number of power plants from each energy technology can be selected (Bessette et al., 2014; Bessette et al., 2016; Mayer et al., 2014). This approach ensures that realistic options are chosen and trade-offs between technologies are made. The present research does not include information about the attributes of the different technologies, for example, their cost or their contribution to air pollution. 
This is in contrast to the approach adopted by Bessette et al. (2014) and Mayer et al. (2014), who focus on delivering decision-making support in complex decision contexts. When information was provided regarding a negative attribute of a given energy technologies it significantly decreased the level of acceptance when compared to the more general level of acceptance seen when no such information was provided (Sütterlin and Siegrist, 2017). Information can, at least during independent evaluations of energy technologies, influence the public's level of acceptance. Although these findings underline the relevance of investigating the impact of information on portfolio choice in environments wherein such information can be compared across technologies, the present study focused on the predictive power of prior attitudes with regards to portfolio choice. Hence, comparable to what Sütterlin and Siegrist (2017) term public acceptance at an abstract (general) vs. concrete level (i.e. mention of negative attributes), we intend to assess portfolio choice at an abstract level, where no information concerning the attributes of different energy technologies are provided. We investigate the relationship between portfolio choice and the explanatory factors that have previously been shown to be significant in relation to the acceptance of individual energy technologies.

\subsection{Explanatory factors - The role of concerns}

People's individual values influence their acceptance of energy technologies (Perlaviciute and Steg, 2015). For instance, environmental values increase the acceptance of solar, wind and natural gas power plants, although such values slightly decrease the acceptance of nuclear power. They also find that valuing energy security increases the acceptance of nuclear power, while it decreases the acceptance of other power sources (Visschers and Siegrist, 2014). Demski et al. (2015) identify public values in relation to the UK's energy system transition, including "environment and nature" or "security and stability" (p.64). We see such values as goals for a future energy system, that is, they are states that should be reached following the transformation of the current energy system. We contend that concerns arise if the achievement of these public values is perceived to be threatened and therefore unlikely. ${ }^{3}$

\footnotetext{
3 The public considers certain consequences and features of the future electricity system to be important, for example, the capacity to achieve a secure and stable energy supply. In the context of energy system change, these considerations have been termed public values (Demski et al., 2015). However, if the public perceives that these valued outcomes will not be achieved, then concerns regarding certain consequences of the electricity system might arise. Hence, we consider that such concerns about perceived negative consequences reflect the opposite of what people value in a future energy system.
} 
Concerns about climate change, the environment, energy security and the economy all appear to be relevant to the acceptance of energy technologies.

\subsubsection{Concern about climate change}

Concern about climate change has often been studied as an explanatory variable for acceptance in the context of nuclear power. Climate change mitigation, when perceived as a benefit of nuclear power, positively influences public acceptance of nuclear power plants (Visschers et al., 2011). If nuclear power is framed as mitigating climate change, public acceptance of it is higher (Pidgeon et al., 2008). Moreover, people who believe that nuclear power helps to mitigate climate change exhibit a lower level of concern about climate change and the environment, and they ultimately show a more positive evaluation of nuclear power (Spence et al., 2010). However, increased support for nuclear power, under the assumption that it mitigates climate change, is conditional. Indeed, it is a prerequisite of this support that the ability of other options to mitigate climate change is exhausted (Corner et al., 2011).

Concern about climate change also influences the acceptance of other energy technologies. The combination of the high perceived risks of nuclear power and higher concern about climate change was related to an increased willingness to pay for renewable sources, such as bioenergy, wind and solar power (Vainio et al., 2017). This corroborates previous findings that higher concern about climate change is related to increased acceptance of renewable energy technologies (Ansolabehere and Konisky, 2014; Spence et al., 2010). However, when asked about the reasons why they endorse renewable technologies, only a minority of respondents actively mentioned climate change mitigation (Ertör-Akyazı et al., 2012).

Concern about climate change is less important in terms of predicting the acceptance of different energy technologies when compared to environmental concern (Spence et al., 2010), perceived environmental harm, or perceived costs (Ansolabehere and Konisky, 2014).

\subsubsection{Concern about the environment}

In terms of the evaluation of technologies, the perceived environmental harm, such as local air pollution, is a consistently relevant attribute (Ansolabehere and Konisky, 2014). Even when measured at a more 
general level, environmental concern influences public acceptance of energy technologies. People who perceive that the environment will be better off in 25 years (i.e. those who exhibit a low level of environmental concern) are more likely to prefer fossil fuels (Greenberg, 2009). In the same study, being actively involved in environmental issues (i.e. a higher level of environmental concern) was related to a lower preference for fossil fuels and a higher preference for renewable energy technologies (Greenberg, 2009). Similarly, a significant positive relationship between environmental concern and the endorsement of renewable energies, but a negative relation with nuclear power, was found in Turkey (Ertör-Akyazı et al., 2012). In general, the public values that electricity is provided in a way that is not harmful to the environment and that does not unnecessarily interfere with nature (Demski et al., 2015). Environmental concerns can, however, potentially decrease support for renewable energies. The environmental damage caused by hydropower plants, wind power or biomass power is frequently cited by nature conservation organisations when seeking to oppose renewable power plants (Anshelm and Simon, 2016).

\subsubsection{Concern about energy security}

Energy security in the form of a reliable, affordable and safe system is important to the public (Demski et al., 2015). Yet, when compared to climate change issues, it has been less broadly discussed (Demski et al., 2014). In Switzerland, views on energy security are known to diverge between experts and the public. While experts favour a highly integrated and efficient system, the public exhibit somewhat contradictory preferences for a system that is both independent from other countries and cheap (Blumer et al., 2015). Energy security predicts the acceptance of energy technologies, as is the case for nuclear power (Corner et al., 2011). This positive relationship between the acceptance of nuclear power and concern about energy security was confirmed in the case of Switzerland (Visschers and Siegrist, 2014). A higher level of concern for energy security, however, decreased the level of acceptance of renewable energies (Visschers and Siegrist, 2014), possibly due to the perceived inefficiency of solar and wind power to deliver enough electricity when needed (Ertör-Akyazı et al., 2012). 


\subsubsection{Concern about the economy}

Economic development and unemployment are recurrent key concerns among the Swiss population (CS and gfs.bern, 2017), and they consistently rank among the top three concerns of Americans (Ansolabehere and Konisky, 2014). With respect to the energy system, concern about the costs of energy technologies and their impact on employment seem to be relevant. The personal financial cost (e.g. price for using electricity) or costs related to subsidies have been suggested to influence people's attitudes towards technologies (Huijts et al., 2012). In a longitudinal study conducted in the USA, the perceived economic costs of energy technologies were found to be increasingly important in relation to their evaluation and acceptance between 2002 and 2011 (Ansolabehere and Konisky, 2014). When provided with information about the price of electricity obtained from different energy technologies, individuals were in favour of an increase in the use of fossil fuels and nuclear power and a decrease in renewable power (Ansolabehere and Konisky, 2012). Price also influences portfolio choices. Individuals indicated a preference for a reduction in their annual electricity premiums (Bessette et al., 2014; Bessette et al., 2016). In addition, the impact on the wider economy (i.e. employment) was relevant (Bessette and Arvai, 2018). The US public also indicated a lower level of support for renewable portfolio standards (i.e. US state laws that require a minimum portion of the electricity mix to be renewable) when they believed that such standards would not create additional jobs (Stokes and Warshaw, 2017).

\subsection{Explanatory factor - The role of affect}

People's judgments are often based on their feelings about an object (Slovic et al., 2004). Such affective reactions can serve as a quick and efficient cue for many decisions (Slovic et al., 2007). Affect demarcates whether the object or representation is perceived as good or bad (Slovic et al., 2007). The positive or negative feelings associated with an object or representation (i.e. the affective pool attached to it) consequently guide its evaluation (Finucane et al., 2000). This means that the affective evaluations of a given energy technology guide the inferences that are made about the associated risks and benefits of that technology, with agreement being seen between the feeling and the ensuing risk or benefit evaluation (Slovic et al., 2004). 
Research concerning the acceptance of technologies found that affect, through risk and benefit perception, influences, e.g. the willingness to buy nanotechnology products (Siegrist et al., 2007) as well as the acceptance of wind, solar, nuclear and natural gas power (Visschers and Siegrist, 2014). The research field concerned with energy systems initially studied affective evaluations of nuclear power. Positive affect was seen to be related to an increase in support for nuclear power, while negative affect was related to a decrease in support. It was hence considered to be an orienting mechanism for acceptance by Peters and Slovic (1996). The same pattern has been corroborated in later studies (Keller et al., 2012; Visschers et al., 2011). More recently, the affective perceptions of energy sources have been investigated in relation to coal, gas and wind power in the USA. With the exception of wind power, people's affective perceptions were significantly related to their support for technologies, explaining more than $30 \%$ of the variance (Truelove, 2012). Acceptance is based on the evoked affect, at least in the case of solar power, particularly when no negative attributes were mentioned in relation to that energy source (Sütterlin and Siegrist, 2017).

\subsection{Study aims}

Previous research has provided insights into the drivers of the acceptance of individual energy technologies, including evoked affect and four different types of concern (i.e. about climate change, the environment, energy security and the economy). General acceptance, however, does not account for the constraints placed on the electricity system, such as the limited potentials of technologies to contribute to domestic power production. Though acceptance provides a generic insight into public acceptance, it fails to deliver insights into preferences for realistic energy portfolios. While decision support systems have used realistic constraints, to the best of our knowledge, this has not been attempted before in an environment, where no information on the consequences of choice are provided. In sum, the main aim of this study is to assess whether and how affect and the four identified types of concern influence the proportion of energy technologies included within portfolios.

The second aim of this study is related to the types of the chosen electricity portfolios, since the public might not exhibit uniform preferences with regards to the future Swiss electricity mix. We explore 
whether the individuals in our sample have similar or dissimilar preferences for the Swiss electricity mix as well as whether these preferences are compatible with the new energy law.

The remainder of this article is structured as follows. We introduce the utilised methods and data analyses in section 2 . In section 3 , we outline the results. In order to answer the first research question, we initially test whether the four theoretically different types of concerns can be identified empirically (section 3.1), and we illustrate the distributions of the affect evoked across all energy technologies (section 3.2). The role of the four types of concerns and affect in predicting the variables of portfolio choice is then considered (section 3.3). Next, we identify the different types of energy portfolios (section 0 ) in order to answer our second research question. The study results and their policy implications are subsequently discussed.

\section{Methods}

\subsection{Sample and procedure}

We collected data via an online study during the second half of September 2017. The respondents were recruited in the German-speaking part of Switzerland from an Internet panel of the Consumer Behavior Group at ETH Zurich. The panel members had previously registered with the panel and agreed to take part in studies on a regular basis. They were invited to participate in this online study via e-mail. No information regarding the aim of the study was provided in the invitation. A reminder e-mail was sent one week after the initial invitation.

First, the respondents selected their preferred portfolio of different energy sources for the Swiss electricity system in the year 2035. Second, the different explanatory factors and sociodemographic variables were assessed via a questionnaire. On average, completion of the questionnaire took 14 minutes. Any respondents who completed the questionnaire in less than 6.13 minutes, which equals half the median completion time ( $M d n=12.26$ minutes), were excluded from the analysis. The final sample size was 317 respondents ( $38.8 \%$ female). Some $5.4 \%$ of respondents were aged 18 to 39 years, $33.1 \%$ were aged between 40 and 59 years, $57.1 \%$ between 60 and 79 years, while $4.4 \%$ were aged 80 to 87 years. The educational level of the sample was slightly higher than that of the general Swiss population (FSO, 2017). 


\subsection{Measures}

\subsubsection{Portfolio choice}

For the portfolio choice task, the respondents were asked to follow the instructions given in Text Box 1. A set of different energy technologies was shown to the respondents, who could in turn select a combination of technologies. In order to be able to submit their portfolio, the respondents had to choose a portfolio that totalled $100 \%$, which was equal to fulfilling the electricity demand on an average winter day in Switzerland, when consumption is at its highest.

\section{Text Box 1. Instructions for portfolio choice task}

\section{Future electricity production in Switzerland}

Imagine that you can define how Switzerland will produce electricity in 2035 according to your preferences.

Your task on the next page is to choose an electricity portfolio that covers at least $100 \%$ of the electricity demand in Switzerland for the year 2035.

The following information is important:

1 Your choice is limited, since you cannot dismantle existing infrastructure.

2 For every technology, you can choose at most the

To ensure that the respondents chose a realistic portfolio, we constrained their choice options. For energy technologies that are already in use today in Switzerland and for which the infrastructure will still be in place in 2035 , the respondents were forced to choose the current capacity as a minimal contribution to their portfolio. Additionally, we restricted their choice so that the respondents could not choose more of an energy technology than its domestic technical capacity would permit. For example, for hydropower, the respondents had to choose a minimum of $45 \%$, since the currently installed power plants deliver on average $45 \%$ of the utilised electricity on a winter day. However, they could maximally choose $47 \%$ hydropower in the portfolio, since the potential to further exploit that energy technology is very limited for Switzerland (SFOE, 2012). The minimum and maximum potentials were determined based on the energy output on an average winter day (Assouline et al., 2017; Díaz et al., 2017; Kienast et al., 2017; Panos and Kannan, 2016). In total, 53\% of the portfolio choice was predetermined. The 
respondents could freely choose the remaining $47 \%$ from the listed technologies in order to reach $100 \%$.

The respondents faced the choice options shown in Figure 1.

Please choose your preferred portfolio for electricity production in the year 2035.

The minimum and maximum a technology can contribute to electricity production in Switzerland are indicated in brackets. The sum of all technologies must equal

$100 \%$ so that demand is completely fulfilled.

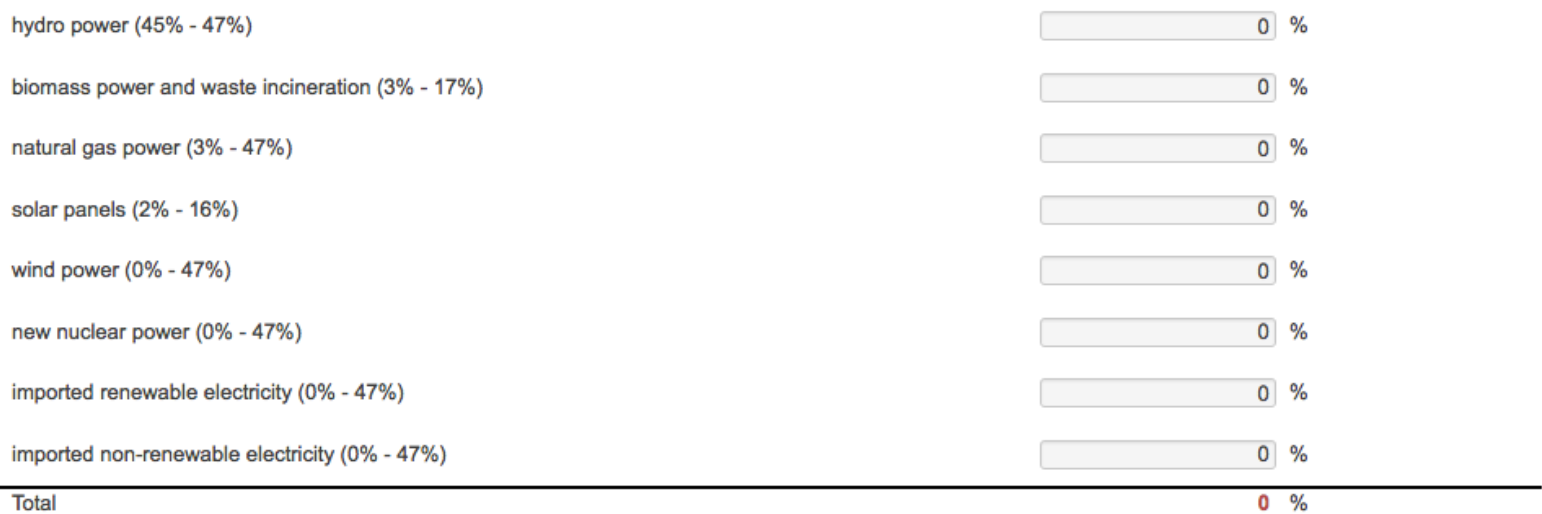

Figure 1. Portfolio choice task in the online study. The respondents were asked to choose $100 \%$ so as to meet the electricity demand on a winter day in Switzerland. The choice was restricted by the percentages indicated in brackets.

\subsubsection{Affect}

After submitting their portfolio, the respondents' affect towards each technology was measured by asking the question "What kind of feelings are being evoked in you when thinking about the following technologies?". All available technologies for the respondents' portfolio choice were shown on one page, each followed by a slide bar with which they could give their response on a scale ranging from 0 "very negative feelings" to 50 "neither positive nor negative" to 100 "very positive feelings". The item to assess affect was retrieved from Lienert et al. (2017). The order of the questions was randomised for each subject.

\subsubsection{Scale for concerns - economy, energy security, environment and climate change}

We measured the four different types of concerns using a set of 16 items. ${ }^{4}$ For concern about the economy, concern about energy security and concern about the environment, the items were preceded

\footnotetext{
${ }^{4} \mathrm{We}$ additionally measured three items that were subsequently not used (see section 3.1). For environmental concern, we measured two additional items, namely "the health of humans is endangered by electricity production" and "electricity production will strongly change the landscape". We adapted these items from a measure of environmental values (Visschers and Siegrist, 2014). For concern about energy security, we also measured "the stocks of fossil resources for electricity production (e.g. gas, uranium, coal) will deplete" (Corner et al., 2011).
} 
by the question "How concerned are you, if at all, that in future...". The respondents answered on a scale ranging from 1 "not concerned at all" to 7 "very concerned". These three types of concerns included the following items:

To measure concern about the economy, we based two items on currently unpublished work by Demski (2017, personal communication) (Table 1, items 1-2). Item 1 measured the general level of concern about economic development. Item 2 investigated the level of concern about job losses. We complemented them with one item referring to concern about a reduced quality of life or well-being (Visschers and Siegrist, 2014) (Table 1, item 3). To account for the costs of the energy technologies (Ansolabehere and Konisky, 2012; Bessette et al., 2014; Bessette et al., 2016), we created the item “... high costs arise for electricity production" (Table 1, item 4).

The questions related to concern about energy security were retrieved from Corner et al. (2011) (Table 1, items 5-9). Currently, the cost of electricity represents only a modest share of household expenditure in Switzerland (Blumer et al., 2015). Therefore, we adapted item 9 regarding the affordability of electricity. Instead of measuring a general concern that electricity might become unaffordable, we asked about the concern that households could not afford electricity in the future.

We created a general item regarding concern about environmental damage due to electricity production (Table 1, item 10), since the public typically values an electricity system that is not harmful to the environment (Demski et al., 2015). Environmental concern has previously been measured more specifically for different environmental issues, e.g. the production of (radioactive) waste (Pidgeon et al., 2008), based on which we incorporated two items (Table 1, item 11-12).

A previously developed set of items regarding concern about climate change (Tobler et al., 2012) followed in the questionnaire (Table 1, items 13-16). For these items, the respondents indicated their degree of agreement on a scale ranging from 1 "I do not agree at all" to 7 "I totally agree".

The items assessing concern about energy security preceded the questions on concern about climate change in order to avoid the subtle framing effects (Demski et al., 2014). 


\subsubsection{Sociodemographic variables}

The sociodemographic variables of age, gender, level of education and political orientation were collected. The respondents' political orientation was measured on a left-right self-placement scale ranging from 1 "completely left" to 10 "completely right" (Breyer, 2015; Rudolf et al., 2014).

\subsection{Data analysis}

For our data analysis, we first performed a principal component analysis (PCA) to reduce the large set of variables related to concerns about impacts on the economy, the environment and energy security to a smaller set of components. To examine the relation between the explanatory factors and the portfolio choice, we conducted separate multiple regression analyses, wherein the chosen proportions of the energy sources were used as dependent variables.

Additionally, we performed a cluster analysis in order to identify different groups of people based on the type of their chosen energy portfolio. The cluster analysis was based on seven of the eight energy technologies. The "hydropower" variable was omitted due to the restricted choice (45-47\%) available to the respondents, which resulted in very little variance in that variable. For all the variables, we subtracted the already installed capacities. This resulted in the proportions for every energy technology that was chosen in addition to the minimum choice imposed by the applied constraints (see section 2.2.1). As all the proportions were measured in percentages, no additional standardisation was implemented. Ward's method was applied, since it leads to similar-sized clusters (Backhaus et al., 2003), together with the squared Euclidian distance as a distance measure.

\section{Results}

\subsection{Identifying concerns}

A PCA was run on the items related to concern about the environment, the economy and energy security. ${ }^{5}$ We visually inspected the scree plot, which revealed that two components should be retained.

\footnotetext{
5 The items related to the concern about climate change were not included in the PCA, since they measured general concern about climate change and hence were not surveyed in direct relation to the electricity system. In order to verify whether some items would cross-load on this separate scale, we performed an additional PCA that included all the items. We found a three-component solution, whereby none of the items in Table 1 cross-loaded strongly on the items measuring concern about climate change. As expected, the existing scale for concern about
} 
Varimax orthogonal rotation was used to enhance the interpretability of the solution. One item ("the health of humans is endangered by electricity production") was deleted due to cross-loading on components one and two. Further, two items were deleted for only weakly loading on component one and thereby reducing the reliability of the scale ("electricity production will strongly change the landscape" and "the stocks of fossil resources for electricity production (e.g. gas, uranium, coal) will deplete"). The PCA was rerun without these items. Yet, the scree plot still revealed two components, which were retained for further analysis. Together, the two components explained $65.12 \%$ of the variance. The variables related to concern about the economy and energy security loaded on a single factor. We termed it "concern about societal costs of electricity production", since energy security issues can also have cost ramifications, whether of a societal or economic nature. The second component subsumed concern about the environmental impacts of electricity production. The reliability was good for both the retained components (Cronbach's $\alpha>.85$ ). The rotated component solution and the respective loadings are presented in Table 1.

\section{Table 1}

Rotated structure matrix for the PCA with varimax rotation for the three components

\begin{tabular}{|c|c|c|c|}
\hline & & $\begin{array}{c}\text { Component } 1 \\
\text { concern about societal costs } \\
\text { of electricity production }\end{array}$ & $\begin{array}{c}\text { Component } 2 \\
\text { concern about environmental } \\
\text { impacts of electricity } \\
\text { production }\end{array}$ \\
\hline 1 & $\begin{array}{l}\text { The Swiss economic performance will reduce } \\
\text { due to the type of electricity production. }\end{array}$ & .78 & .14 \\
\hline 2 & $\begin{array}{l}\text { Jobs will disappear in the Swiss electricity } \\
\text { sector. }\end{array}$ & .76 & .13 \\
\hline 3 & $\begin{array}{l}\text { Our well-being will be reduced due to the } \\
\text { type of electricity production. }\end{array}$ & .84 & -.02 \\
\hline 4 & High costs arise for electricity production. & .69 & -.08 \\
\hline 5 & Electricity will be rationed & .85 & .03 \\
\hline 6 & Power outages will occur & .78 & .02 \\
\hline 7 & $\begin{array}{l}\text { Switzerland will be too dependent on } \\
\text { electricity from abroad. }\end{array}$ & .72 & .20 \\
\hline 8 & $\begin{array}{l}\text { Terrorist attacks will interrupt the electricity } \\
\text { supply. }\end{array}$ & .68 & .23 \\
\hline 9 & $\begin{array}{l}\text { Private households will not be able to afford } \\
\text { electricity }\end{array}$ & .82 & .15 \\
\hline 10 & $\begin{array}{l}\text { Electricity production negatively impacts the } \\
\text { environment }\end{array}$ & .07 & .89 \\
\hline
\end{tabular}

climate change loaded on a separate component, with a reliability of $\alpha=.94$. The solution for the first two components remained stable. 


\begin{tabular}{llc}
11 & .13 & $\mathbf{. 8 9}$ \\
12 & & \\
& $\begin{array}{l}\text { Electricity production contributes to a } \\
\text { changing climate. }\end{array}$ & $\mathbf{. 8 2}$ \\
Waste is being produced during electricity & & 18.40 \\
production. & 46.72 & 0.85 \\
\hline \%of variance & 0.92 & 0.92 \\
\hline
\end{tabular}

Note: Items were preceded by the question "How concerned are you, if at all, that in future...".

\subsection{Affect evoked across the energy technologies}

We assessed the distributions of the affect evoked by each energy technology using box plots (Figure 2). The distributions of affect were not uniform across the energy technologies. We observed that for hydropower $(M d n=89.0, I Q R=21.5)$ and solar panels ( $M d n=90.0, I Q R=25.0)$, some $75 \%$ of respondents showed positive affect towards these technologies. The distributions for wind ( $M d n=70.0, I Q R=34.50$ ) and biomass power $(M d n=70.0, I Q R=33.0)$ showed that at least $75 \%$ of respondents exhibited a neutral or positive affect towards these technologies. However, the respondents indicated their affect in relation to imported renewable electricity $(M d n=50.0, \mathrm{I} Q R=24.0)$ to be closer to being neither positive nor negative. Some $75 \%$ of respondents indicated their affect for natural gas to be negative, that is, lower 
than the mid-point $(M d n=41.0, \mathrm{I} Q R=33.0)$. Nuclear power $(M d n=2.0, \mathrm{I} Q R=23.5)$ evoked mainly negative affect, similar to non-renewable imports $(M d n=3.0, I Q R=15.5)$.

Distributions affect by energy technology

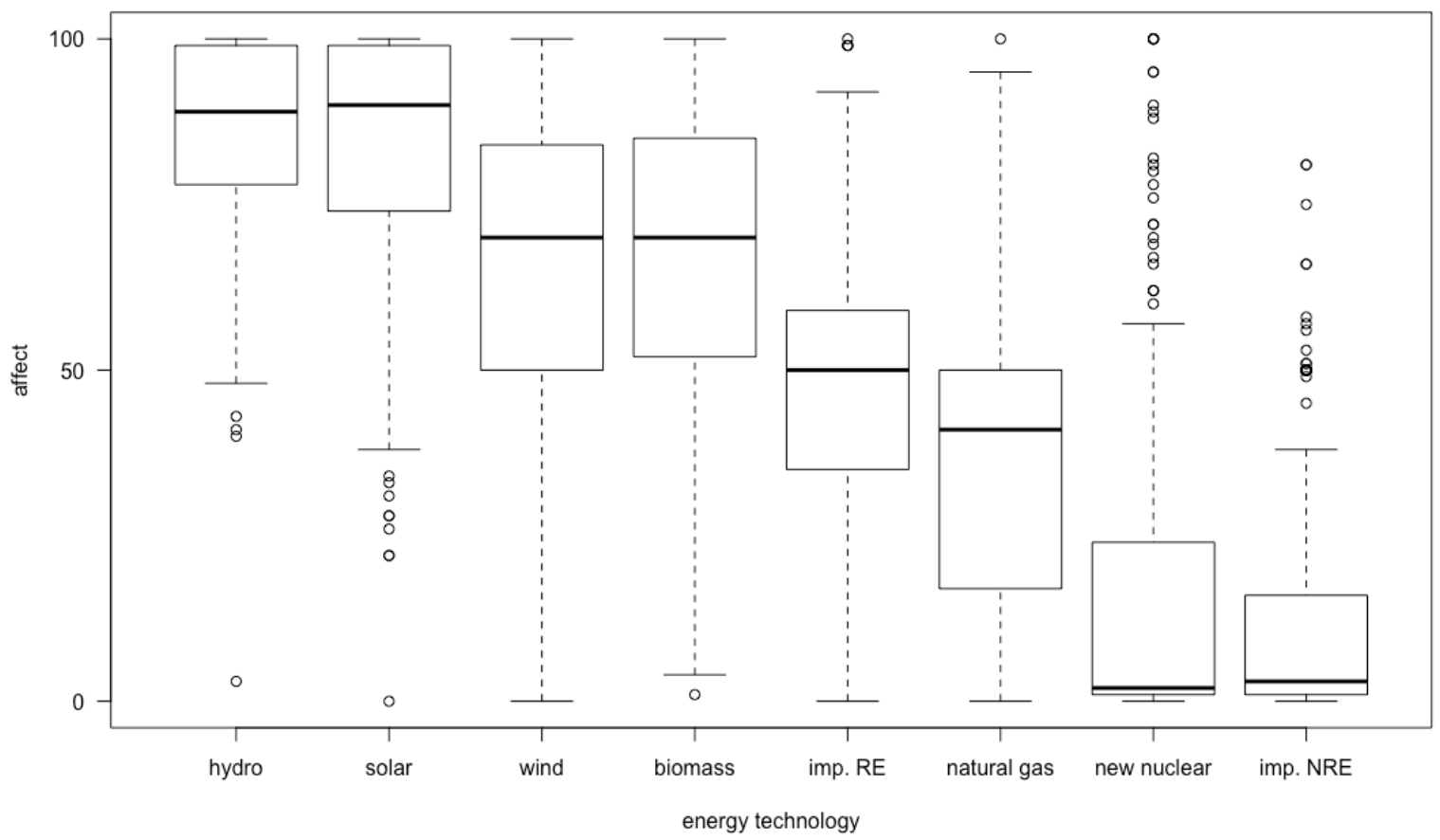

Figure 2. Box plot of affect by energy technology, displaying the median, $25^{\text {th }}$ and $75^{\text {th }}$ percentiles. Distributions are shown for hydropower (hydro), solar panels (solar), wind power (wind), biomass and waste incineration (biomass), imported renewable electricity (imp. RE), natural gas power (natural gas), new nuclear power (new nuclear) and imported non-renewable electricity (imp. NRE).

\subsection{Predicting the chosen proportions of energy technologies}

We ran separate multiple regression analyses in order to predict the proportions of an energy technology that the respondents chose for inclusion in their portfolio. We included the sociodemographic variables of age, gender, level of education and political orientation, as well as affect for the respective energy technology, concern about climate change, concern about environmental impacts and concern about societal costs of electricity production, as independent variables. All the multiple regression models significantly predicted the selected proportions of the energy technologies (see Table 2 and Table 3 ).

Affect was a significant, as well as the most important, predictor of the proportions of the energy technologies in all the regression models $(0.33<\beta>0.72, \mathrm{p}<.001)$. For the proportion of nuclear power, the model explained $54 \%$ of the variance, with only affect being a significant predictor. We observed 
the same pattern for wind power (33\% of the variance explained) and the proportion of biomass and waste ( $27 \%$ of the variance explained). The explained variance for the proportion of total renewable technologies, solar power and natural gas power was also high, ranging between $24 \%$ and $37 \%$. The regression models for hydropower, imported renewable power and imported non-renewable power explained less variance, ranging between $13 \%$ and $15 \%$. For hydropower, this is due to the imposed constraints (see section 2.2.1) resulting in low variability in the given answers. In some of the models, the concerns or sociodemographic variables were significant, albeit less important in terms of predicting the chosen percentages when compared to affect (see Table 2 and Table 3). In contrast, the different types of concerns did not consistently exhibit a direct effect on the chosen proportions across all the energy technologies. Indeed, we only found a direct effect of all three concerns on the composite variable encompassing the sum of the renewable energy proportions (see Table 2, "total renewable proportion"). Further, while concern about climate change $(\beta=0.19, \mathrm{p}<.001)$ and concern about the environmental impacts of electricity production $(\beta=0.16, \mathrm{p}<.001)$ both increased the proportion of the total renewables chosen, concern about societal costs of electricity production reduced the chosen amount $(\beta=-0.17, \mathrm{p}<.001)$. Moreover, concern about climate change had a statistically significant negative effect on the chosen proportion of imported non-renewable energy $(\beta=-0.14, p<.05)$, while concern about societal costs showed a statistically significant positive effect on the chosen proportion of natural gas power $(\beta=0.11, p<.05)$. The non-standardised regression coefficients and confidence intervals can be seen in Table 2 and Table 3 . 


\section{Table 2}

Multiple regression analyses concerning the proportions of energy technologies chosen for the portfolio.

\begin{tabular}{|c|c|c|c|c|c|c|c|c|c|c|c|c|}
\hline & \multicolumn{3}{|c|}{ Total renewable proportion } & \multicolumn{3}{|c|}{ New nuclear } & \multicolumn{3}{|c|}{ Natural gas } & \multicolumn{3}{|c|}{ Imported non-renewable } \\
\hline & $\mathrm{B}$ & $95 \% \mathrm{CI}$ & $\beta$ & B & $95 \% \mathrm{CI}$ & $\beta$ & B & $95 \% \mathrm{CI}$ & $\beta$ & $\mathrm{B}$ & $95 \% \mathrm{CI}$ & $\beta$ \\
\hline Constant & 65.42 & {$[55.61,75.23]$} & $* * *$ & -5.20 & {$[-11.77,1.37$} & & 1.80 & {$[-4.10,7.70]$} & & 1.05 & {$[-1.71,3.77$} & \\
\hline Gender & .88 & {$[-1.02,2.78]$} & .04 & .31 & {$[-1.07,1.68]$} & .02 & -.20 & {$[-1.50,1.11]$} & -.02 & .26 & {$[-.34, .85]$} & .05 \\
\hline Age & -.06 & {$[-.13, .01]$} & -.08 & .00 & {$[-.05, .05]$} & .00 & .02 & {$[-.03, .07]$} & .04 & .02 & {$[.00, .04]$} & .09 \\
\hline Level of education & -.56 & {$[-1.12, .01]$} & -.09 & .25 & {$[-.16, .66]$} & .05 & -.02 & {$[-.40, .36]$} & -.01 & .09 & {$[-.09, .27]$} & .05 \\
\hline Political orientation & -.48 & {$[-1.07, .11]$} & -.08 & .15 & {$[-.28, .58]$} & .03 & -.05 & {$[-.45, .34]$} & -.02 & -.11 & {$[-.30, .07]$} & -.07 \\
\hline Affect towards [technology] & .31 & {$[.23, .40]$} & $.36^{* * *}$ & .24 & {$[.21, .28]$} & $.72 * * *$ & .13 & {$[.10, .15]$} & $.48 * * *$ & .05 & {$[.03, .07]$} & $.33 * * *$ \\
\hline Concern climate change & 1.51 & {$[.60,2.41]$} & $.19 * * *$ & .01 & {$[-.66, .69]$} & .00 & -.37 & {$[-.96, .22]$} & -.08 & -.31 & {$[-.58,-.02]$} & $-.14 *$ \\
\hline $\begin{array}{l}\text { Concern environmental } \\
\text { impacts }\end{array}$ & 1.14 & {$[.36,1.91]$} & $.16^{* *}$ & .04 & {$[-.54, .63]$} & .01 & -.03 & {$[-.54, .49]$} & -.01 & -.01 & {$[-.27, .23]$} & -.01 \\
\hline Concern societal costs & -1.15 & {$[-1.83,-.46]$} & $-.17 * * *$ & .23 & {$[.27, .73]$} & .04 & .47 & {$[-.02, .93]$} & $.11 *$ & -.11 & {$[-.31, .14]$} & -.06 \\
\hline $\mathrm{R}^{2}$ adjusted & \multicolumn{3}{|c|}{.37} & \multicolumn{3}{|c|}{.54} & \multicolumn{3}{|c|}{.24} & \multicolumn{3}{|c|}{.14} \\
\hline $\mathrm{F}(\mathrm{df} 1, \mathrm{df} 2)$ & \multicolumn{3}{|c|}{$24.59 * * *(8,308)$} & \multicolumn{3}{|c|}{$46.69^{* * *}(8,308)$} & \multicolumn{3}{|c|}{$13.36^{* * *}(8,308)$} & \multicolumn{3}{|c|}{$7.60 * * *(8,308)$} \\
\hline
\end{tabular}

Note: For the total of all the renewable energy sources, as well as for each of the energy technologies, a separate multiple regression analysis was conducted. For the analysis of the total renewable proportion chosen in the portfolio, the chosen proportions of solar, wind, biomass and waste, hydro as well as imported renewable were summed to form the new dependent variable. B is the nonstandardised regression coefficient. For $B$, the $95 \%$ confidence interval is shown. $\beta$ is the standardised regression coefficient. Significance: ${ }^{*} p<0.05 ; * * p<0.01$; and $* * * p<0.001$. Dummy variable gender: $1=$ female, $2=$ male. The measure of affect is specific to every energy technology. No other variables change across the energy technologies. 


\section{Table 3}

Multiple regression analyses concerning the proportions of renewable energy technologies chosen for the portfolio.

\begin{tabular}{|c|c|c|c|c|c|c|c|c|c|c|c|c|c|c|c|}
\hline & \multicolumn{3}{|c|}{ Solar } & \multicolumn{3}{|c|}{ Wind } & \multicolumn{3}{|c|}{ Biomass and waste } & \multicolumn{3}{|c|}{ Hydro } & \multicolumn{3}{|c|}{ Imported renewable } \\
\hline & B & $95 \% \mathrm{CI}$ & $\beta$ & B & $95 \% \mathrm{CI}$ & $\beta$ & B & $95 \% \mathrm{CI}$ & $\beta$ & B & $95 \% \mathrm{CI}$ & $\beta$ & B & $95 \% \mathrm{CI}$ & $\beta$ \\
\hline Constant & 5.27 & {$[1.32,9.22]$} & $* *$ & 2.07 & {$[-7.19,11.34]$} & & 7.51 & {$[2.49,12.52]$} & $* *$ & 44.69 & $\begin{array}{l}{[43.64} \\
45.74]\end{array}$ & $* * *$ & -6.53 & $\begin{array}{l}{[-13.62} \\
0.56]\end{array}$ & \\
\hline Gender & .07 & {$[-.72, .86]$} & .01 & -.26 & {$[-2.26,1.73]$} & -.01 & -.48 & {$[-1.51, .56]$} & -.05 & .10 & {$[-.12, .32]$} & .05 & 1.35 & $\begin{array}{l}{[-.20} \\
2.89]\end{array}$ & .10 \\
\hline Age & .00 & {$[-.03, .02]$} & -.02 & -.05 & {$[-.13, .02]$} & -.07 & .01 & {$[-.03, .05]$} & .03 & -.01 & {$[-.02, .00]$} & $-.13 *$ & .03 & {$[-.02, .09]$} & .06 \\
\hline Level of education & -.12 & {$[-.36, .11]$} & -.05 & -.27 & {$[-.86, .33]$} & -.04 & -.17 & {$[-.48, .14]$} & -.05 & .03 & {$[-.04, .09]$} & .04 & .15 & {$[-.32, .61]$} & .03 \\
\hline Political orientation & -.27 & {$[-.52,-.03]$} & $-.12 *$ & .18 & {$[-.44, .80]$} & .03 & -.22 & {$[-.54, .11]$} & -.07 & -.02 & {$[-.09, .05]$} & -.04 & .21 & {$[-.27, .69]$} & .05 \\
\hline $\begin{array}{l}\text { Affect towards } \\
\text { [technology] }\end{array}$ & .10 & {$[.07, .12]$} & $.44^{* * *}$ & .20 & {$[.17, .24]$} & $.53 * * *$ & .12 & {$[.10, .15]$} & $.51 * * *$ & .02 & {$[.02, .03]$} & $.35^{* * *}$ & .12 & {$[.08, .15]$} & $.37 * * *$ \\
\hline Concern climate change & .32 & {$[-.05, .69]$} & .10 & .62 & {$[-.36,1.60]$} & .08 & -.47 & {$[-.95,-.01]$} & -.12 & .01 & {$[-.10, .11]$} & .01 & -.17 & {$[-.89, .54]$} & -.03 \\
\hline $\begin{array}{l}\text { Concern environmental } \\
\text { impacts }\end{array}$ & .17 & {$[-.15, .49]$} & .06 & .17 & {$[-.65, .98]$} & .02 & .22 & {$[-.20, .65]$} & .06 & -.08 & {$[-.17,-.01]$} & -.12 & .27 & {$[-.36, .90]$} & .06 \\
\hline Concern societal costs & -.13 & {$[-.42, .15]$} & -.05 & -.31 & {$[-1.02, .41]$} & -.04 & -.06 & {$[-.43, .31]$} & -.02 & .03 & {$[-.05, .11]$} & .04 & -.17 & {$[-.72, .38]$} & -.04 \\
\hline $\begin{array}{l}\mathrm{R}^{2} \text { adjusted } \\
\mathrm{F}(\mathrm{df} 1, \mathrm{df} 2)\end{array}$ & \multicolumn{3}{|c|}{$\begin{array}{c}.31 \\
1907 * * *(8)\end{array}$} & \multicolumn{3}{|c|}{$\begin{array}{c}.33 \\
20.41 * * *(8,3\end{array}$} & \multicolumn{3}{|c|}{$\begin{array}{c}.27 \\
15.66^{* * *}(8,3\end{array}$} & \multicolumn{3}{|c|}{$\begin{array}{c}.13 \\
6.87 * * *(8,308)\end{array}$} & \multicolumn{3}{|c|}{$\begin{array}{c}.15 \\
8.12 * * *(8,3\end{array}$} \\
\hline
\end{tabular}

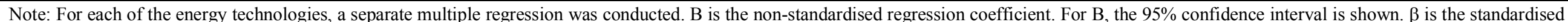

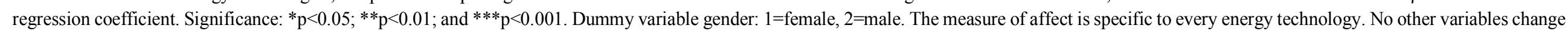
across the energy technologies. 


\subsection{Identifying different types of energy portfolios}

We determined the number of clusters based on the dendrogram and the interpretability of results. The dendrogram indicated a three or four-cluster solution. The four-cluster solution provided a meaningful distinction with regards to the clustering variables. As the variances of the clustering variables strongly differed across the clusters, we conducted a one-way Welch ANOVA with the four-cluster solution, which revealed significant differences between the clusters for all the clustering variables (Table 4). Significant differences between the cluster groups were identified using the Games-Howell post-hoc test for unequal variances. We tested for differences in the added descriptive variables using a one-way ANOVA with Bonferroni post-hoc tests in order to further portray the cluster solution. Significant differences were found for all the descriptive variables between the cluster groups, except for the level of education (Table 5).

We identified four clusters of people with different portfolio compositions. Cluster 1 (48.6\%) preferred wind power, cluster 2 (18.6\%) chose more natural gas and biomass, cluster 3 (6.3\%) favoured new nuclear power and cluster 4 (26.5\%) placed a stronger emphasis on renewable imports than the other groups.

The largest cluster, wind power, comprised 154 respondents. They chose a significantly larger amount of wind power in their portfolio $(23.33 \%)$ than all the other groups. In addition, the people in this cluster added a high number of solar panels (12.04\%), followed by biomass power and waste incineration $(8.56 \%)$. In general, they primarily selected renewable electricity produced in the country and no imported electricity from abroad (Table 4). This cluster showed high concern for climate change, relatively high concern for environmental impacts of power generation and medium concern about the costs that could be imposed on society due to electricity production. On average, the people in this cluster exhibited significantly more positive feelings towards renewable power plants than those in the other groups. Slightly more men than women wanted a portfolio with a strong emphasis on wind power and other domestic renewables (Table 5). 


\section{Table 4}

Four-cluster solution - characterisation of respondents according to the clustering variables.

\begin{tabular}{llllll}
\hline & $\begin{array}{l}\text { Cluster 1 } \\
\text { Wind power } \\
(\mathrm{n}=154)\end{array}$ & $\begin{array}{l}\text { Cluster 2 } \\
\text { Natural gas and } \\
\text { biomass power } \\
(\mathrm{n}=59)\end{array}$ & $\begin{array}{l}\text { Cluster } 3 \\
\text { New nuclear } \\
\text { power } \\
(\mathrm{n}=20)\end{array}$ & $\begin{array}{l}\text { Cluster 4 } \\
\text { Renewable } \\
\text { imports } \\
(\mathrm{n}=84)\end{array}$ & $\begin{array}{l}\text { Welch's F } \\
(\mathrm{df1}, \mathrm{df2})\end{array}$ \\
\hline Biomass and waste & $8.56 \mathrm{a}$ & $11.56 \mathrm{~b}$ & $4.10 \mathrm{c}$ & $9.14 \mathrm{a}$ & $F(3,79.98)=19.10$ \\
incineration & $(5.39)$ & $(3.52)$ & $(4.18)$ & $(4.47)$ & $* * *$ \\
Natural gas & $1.00 \mathrm{a}$ & $13.95 \mathrm{~b}$ & $0.75 \mathrm{ac}$ & $1.42 \mathrm{ac}$ & $F(3,96.35)=73.74$ \\
& $(2.11)$ & $(6.63)$ & $(.97)$ & $(2.43)$ & $* * *$ \\
Solar panels & $12.04 \mathrm{a}$ & $11.81 \mathrm{a}$ & $4.05 \mathrm{c}$ & $10.94 \mathrm{a}$ & $F(3,73.81)=22.72$ \\
& $(3.40)$ & $(3.51)$ & $(4.19)$ & $(3.37)$ & $* * *$ \\
Wind power & $23.33 \mathrm{~b}$ & $5.73 \mathrm{a}$ & $3.3 \mathrm{a}$ & $8.23 \mathrm{c}$ & $F(3,85.33)=243.6$ \\
& $(6.29)$ & $(4.84)$ & $(3.74)$ & $(5.55)$ & $0 * * *$ \\
New nuclear & $.05 \mathrm{a}$ & $.08 \mathrm{a}$ & $32.2 \mathrm{~b}$ & $1.85 \mathrm{c}$ & $F(3,64.76)=79.31$ \\
& $(.44)$ & $(.65)$ & $(9.49)$ & $(4.46)$ & $* * *$ \\
Imported renewable & $1.22 \mathrm{a}$ & $2.75 \mathrm{a}$ & $1.2 \mathrm{a}$ & $12.48 \mathrm{~b}$ & $F(3,79.44)=53.15$ \\
& $(3.23)$ & $(4.12)$ & $(2.53)$ & $(7.85)$ & $* * *$ \\
Imported non- & $.01 \mathrm{a}$ & $.25 \mathrm{a}$ & $.90 \mathrm{ab}$ & $2.07 \mathrm{~b}$ & $F(3,61.30)=6.93$ \\
renewable & $(.16)$ & $(1.04)$ & $(3.35)$ & $(4.60)$ & $* * *$ \\
\hline
\end{tabular}

Note: One-way Welch ANOVAs revealed significant effects for all clustering variables. Significant effects are marked with an asterisk: ${ }^{*} \mathrm{p}<.05, * * \mathrm{p}<.01$ and ${ }^{* * *} \mathrm{p}<.001$. Means are reported for all the clustering variables and cluster groups, and they represent the chosen $\%$ of the energy source in addition to the already installed capacities (53\%).

Pairwise comparisons between the clusters were performed using Games-Howell post-hoc tests for unequal variances. The standard deviation is shown in brackets. Different letters indicate significant differences between the groups at the $\mathrm{p}<.05$ level.

\section{Table 5}

Four-cluster solution - characterisation of the cluster groups with respect to the descriptive variables.

\begin{tabular}{|c|c|c|c|c|c|}
\hline & $\begin{array}{l}\text { Cluster } 1 \\
\text { Wind power } \\
(n=154)\end{array}$ & $\begin{array}{l}\text { Cluster } 2 \\
\text { Natural gas } \\
\text { and biomass } \\
\text { power } \\
(\mathrm{n}=59)\end{array}$ & $\begin{array}{l}\text { Cluster } 3 \\
\text { New nuclear } \\
\text { power } \\
(n=20)\end{array}$ & $\begin{array}{l}\text { Cluster } 4 \\
\text { Renewable } \\
\text { imports } \\
(n=84)\end{array}$ & $\mathrm{F}(\mathrm{df} 1, \mathrm{df} 2)$ \\
\hline $\begin{array}{l}\text { Concern climate } \\
\text { change }\end{array}$ & $\begin{array}{l}6.4 \mathrm{a} \\
(0.90)\end{array}$ & $\begin{array}{l}6.15 \mathrm{ab} \\
(1.07)\end{array}$ & $\begin{array}{l}4.68 \mathrm{c} \\
(1.72)\end{array}$ & $\begin{array}{l}5.83 \mathrm{~b} \\
(1.49)\end{array}$ & $\begin{array}{l}F(3,313)=14.65 \\
* * *\end{array}$ \\
\hline $\begin{array}{l}\text { Concern environmental } \\
\text { impacts }\end{array}$ & $\begin{array}{l}5.46 \mathrm{a} \\
(1.34)\end{array}$ & $\begin{array}{l}5.30 \mathrm{a} \\
(1.30)\end{array}$ & $\begin{array}{l}3.87 \mathrm{~b} \\
(1.72)\end{array}$ & $\begin{array}{l}5.06 \mathrm{a} \\
(1.47)\end{array}$ & $F(3,313)=8.26 * * *$ \\
\hline Concern societal costs & $\begin{array}{l}4.06 \mathrm{ab} \\
(1.45)\end{array}$ & $\begin{array}{l}4.59 \mathrm{ac} \\
(1.45)\end{array}$ & $\begin{array}{l}5.11 \mathrm{c} \\
(1.23)\end{array}$ & $\begin{array}{l}3.88 \mathrm{~b} \\
(1.38)\end{array}$ & $F(3,313)=6.11 * * *$ \\
\hline $\begin{array}{l}\text { Affect renewable } \\
\text { power plants }\end{array}$ & $\begin{array}{l}73.35 \mathrm{~b} \\
(9.16)\end{array}$ & $\begin{array}{l}67.16 \mathrm{a} \\
(12.04)\end{array}$ & $\begin{array}{l}53.18 \mathrm{c} \\
(13.87)\end{array}$ & $\begin{array}{l}69.20 \mathrm{a} \\
(10.26)\end{array}$ & $F(3,313)=24.51 * * *$ \\
\hline Age & $\begin{array}{l}59.11 \mathrm{a} \\
(13.65)\end{array}$ & $\begin{array}{l}63.69 \mathrm{a} \\
(10.99)\end{array}$ & $\begin{array}{l}61.05 \mathrm{a} \\
(12.21)\end{array}$ & $\begin{array}{l}63.35 \mathrm{a} \\
(12.73)\end{array}$ & $F(3,313)=2.87 *$ \\
\hline Political orientation & $\begin{array}{l}5.02 \mathrm{a} \\
(1.69)\end{array}$ & $\begin{array}{l}5.41 \mathrm{a} \\
(1.51)\end{array}$ & $\begin{array}{l}7.05 \mathrm{~b} \\
(1.32)\end{array}$ & $\begin{array}{l}5.38 \mathrm{a} \\
(1.78)\end{array}$ & $F(3,313)=8.98 * * *$ \\
\hline Level of education & $\begin{array}{l}4.79 \\
(1.56)\end{array}$ & $\begin{array}{l}4.58 \\
(1.55)\end{array}$ & $\begin{array}{l}5.00 \\
(1.75)\end{array}$ & $\begin{array}{l}5.00 \\
(1.58)\end{array}$ & $F(3,313)=.95$ \\
\hline Male $(\%)^{+}$ & $0.58 \mathrm{a}$ & $0.42 \mathrm{a}$ & $0.75 \mathrm{ab}$ & $0.76 \mathrm{~b}$ & $\chi^{2}(3)=18.85^{* * *}$ \\
\hline $\begin{array}{l}\text { Note: One-way ANOV } \\
\text { marked with an asterisk } \\
\text { groups. Pairwise compa } \\
\text { shown in brackets. Diff } \\
+ \text { A Chi-square test was } \\
\text { analysis involved pairw }\end{array}$ & $\begin{array}{l}\text { evealed signi } \\
<.05, * * \mathrm{p}<.0 \\
\text { ons between th } \\
\text { t letters indic } \\
\text { nducted for } \mathrm{g} \\
\text { comparisons }\end{array}$ & $\begin{array}{l}\text { effects for sev } \\
k * * p<.001 . \mathrm{M} \\
\text { ters were perf } \\
\text { nificant differ } \\
\text { indicating the } \\
\text { he z-test of th }\end{array}$ & $\begin{array}{l}\text { the eight desc } \\
\text { are reported fc } \\
\text { d using Bonfe } \\
\text { between the } \\
\text { proportion w } \\
\text { portions with }\end{array}$ & $\begin{array}{l}\text { variables. S } \\
\text { he descriptiv } \\
\text { ost-hoc test } \\
\text { at the } p<.05 \\
\text { he different } \mathrm{c} \\
\text { ferroni corre }\end{array}$ & $\begin{array}{l}\text { ant effects are } \\
\text { tes and cluster } \\
\text { tandard deviation is } \\
\text { The post-hoc }\end{array}$ \\
\hline
\end{tabular}


The second cluster, natural gas and biomass power, included 59 respondents. When compared to all the other groups, they chose the significantly largest amount of natural gas power (13.59\%) as well as the significantly largest amount of power generated by biomass and waste incineration (11.56\%). In addition, they added a high percentage of solar panels (11.81\%), but little wind power (5.73). Similar to cluster 1, they included almost no imported electricity or new nuclear power (Table 4). Their concern regarding climate change and the environmental impacts of electricity production was about as high as in cluster 1, and they also exhibited relatively high concern for resulting societal costs. The feelings evoked by renewable energy technologies were significantly lower than those seen for cluster 1, albeit still positive. Slightly more women than men selected a portfolio with high proportions of natural gas and biomass (Table 5).

The third and smallest cluster, new nuclear power, consisted of 20 respondents. For their portfolio, they relied most heavily on new nuclear power plants (32.2\%), choosing a significantly larger amount than all the other groups. Furthermore, they chose a small amount of wind power (3.3\%), which was similar to cluster 2. They further added renewable energy in the form of biomass and waste incineration (4.1\%) and solar panels (4.05\%), but significantly less so than all the other groups. However, similar to clusters 1 and 2, the new nuclear power group predominantly did not choose to import electricity from abroad (Table 4). This group displayed the significantly lowest concern for climate change and environmental impacts of power generation, although they showed significantly higher concern for resulting societal costs than groups 1 and 4. Moreover, their feelings towards renewable energy technologies were close to the midpoint, indicating them to be neither positive nor negative. However, the evoked feelings were significantly more negative when compared to those of all the other groups. Politically, they were oriented significantly more to the right than the other clusters. Males were more likely to choose this portfolio composition than females (Table 5).

The fourth cluster, renewable imports, contained 84 respondents. This group chose a significantly higher proportion of renewable imported electricity (12.48\%) than all the other groups. They chose electricity from solar panels (10.94\%) at similar levels to those in clusters 1 and 2, and a comparable amount of electricity from biomass and waste incineration (9.14\%) to those in cluster 1. Individuals in 
this group added some wind power (8.23\%), lying somewhere between clusters 2 and 3 . They only included low amounts of new nuclear power or natural gas, indicating a clear preference for renewable energy sources, whether domestic or foreign (Table 4). They exhibited significantly lower concern about climate change than individuals in cluster 1, but significantly higher concern than those in cluster 3. Together with cluster 1 , they showed significantly lower concern for societal costs due to electricity production. Additionally, the affect associated with renewable technologies was significantly higher than that seen in cluster 3, but significantly lower than in cluster 1 . Males were more likely to choose this kind of portfolio than females (Table 5).

\section{Discussion and policy implications}

We investigated a more realistic and therefore more relevant dependent variable for energy technology preference than that considered in most prior studies. Rather than measuring acceptance of individual energy technologies, we took a closer look at people's preferences for electricity portfolios. To that end, we assessed our respondents' preferences for the future electricity mix in Switzerland under realistic constraints. This meant that the amount the respondents were able to choose for each energy technology was constrained by its technical potential to contribute to domestic electricity production. Consequently, the respondents had to choose a combination of different technologies for generating electricity. To a certain extent, this reflects a more deliberative approach, since trade-offs between technologies had to be made.

We found similar results to those presented in the acceptance literature (Ertör-Akyazı et al., 2012; Greenberg, 2009; Spence et al., 2010; Truelove, 2012) concerning the effect of explanatory factors on electricity mix preferences. Affect was the most relevant predictor of the proportion of all eight investigated energy technologies. People's affective reactions to energy technologies guide the percentages included in their preferred electricity portfolio. Concerns about climate change, the environmental impacts and societal costs of electricity production additionally predicted the total renewables proportion. However, they did not influence the proportion of nuclear power (Table 2) or the different renewable energy technologies when they were analysed in separate regression models 
(Table 3). The four types of concerns had lower and inconsistent influences on the other investigated energy technologies.

The regression models explained high shares of the variance, namely $54 \%$ for nuclear, $31 \%$ for solar and $33 \%$ for wind power. This underlines the importance of the affect heuristic, previously emphasised by Truelove (2012). In contrast to her results, we find that affect has a high explanatory power even for wind power. In view of the fact that the choice options available for the respondents were restricted, the explained variance and thus the explanatory power of affect are high. When it comes to choosing a portfolio that combines different energy technologies, we seem to largely choose what we spontaneously like.

In addition, we more closely examined the energy portfolio preferences. The investigated sample did not exhibit uniform preferences for the future electricity mix. In fact, we identified four different clusters of people with different types of portfolios. The typical portfolio in cluster 1 was dominated by wind power, with the addition of other domestic renewable energy technologies. Cluster 2 favoured natural gas and biomass power, with added domestic renewable energy technologies. Cluster 3 was less inclined towards renewable technologies and chose new nuclear power to a significantly greater extent in their portfolio. Lastly, cluster 4 also chose domestic renewable energy technologies, but additionally included a higher proportion of renewable imports.

The four identified clusters show that the preferences demonstrated in our sample were different and sometimes diverging. The first difference between the clusters is related to independence from electricity generated abroad. A majority of respondents preferred an independent domestic energy supply (clusters 1, 2 and 3), reflecting the public views found by Blumer et al. (2015). Only one group was open to imports (cluster 4). It is not surprising that only a minority of respondents were in favour of a system that imports electricity from abroad. Demski et al. (2014) showed a high share of people in the UK $(83 \%)$ to be very or fairly concerned about energy dependence on other countries. Secondly, cluster 2 (natural gas and biomass power), who exhibited a somewhat higher concern about societal costs of electricity production, chose to complement renewable energies with natural gas power. This cluster appears to be discordant with clusters 1 and 4, who chose to rely mainly on renewable technologies. The third difference we identified concerns the fact that the new nuclear power cluster 
contrasts with the other three clusters in terms of their preference for nuclear power over renewable energy technologies in order to meet the electricity demand.

The clusters were different with respect to a set of characterisation variables. On the one hand, cluster 3 (new nuclear power) showed significantly lower concern about climate change and the environment, and somewhat higher concern about the societal costs of electricity production. Previously, pro-nuclear groups were found to place greater emphasis on the economic benefits of nuclear power when compared to anti-nuclear groups (Eiser and Van der Pligt, 1979). The level of concern about societal costs was the highest in the two subgroups that included high percentages of either nuclear power (cluster 3) or natural gas (cluster 2). This could be linked to the perceived inefficiency of renewables in terms of delivering a stable energy supply due to intermittent electricity generation (Ertör-Akyazı et al., 2012), and/or the perceived benefit of nuclear power in promoting a stable and reliable supply (Corner et al., 2011; Pidgeon et al., 2008; Spence et al., 2010). Whereas, cluster 4 indicated the lowest level of concern about the societal costs of power generation, choosing significantly larger amounts of renewable imports, which has been described as the most cost-effective alternative to nuclear power in Switzerland (Pattupara and Kannan, 2016). Different portfolio preferences are reflected in part at least in the different levels of concern seen across the clusters, although we note that clusters 1 and 2 did not differ significantly in that respect. When looking at the regression analyses, the three types of concerns proved significant in terms of predicting the total proportion of renewables within portfolios, although they were only sporadically related to the proportions of the individual technologies. This effect is mirrored in the characterisation of the clusters in relation to the three types of concerns. The difference in the levels of concern between the clusters seems to be due to how strongly those concerns drive the inclusion of renewable technologies in portfolios. Such effects of concerns are noteworthy. Compared to the affective reactions, the measures of concerns are more distant from the individual energy technologies, relating to a global concern about climate change or impacts of the electricity system. Thus, concerns seem to be background factors that affect portfolio preferences in addition to the affective reactions individual energy technologies evoke. 
The above-mentioned properties and observed differences between the clusters, could have ramifications for the implementation of the new energy law in Switzerland. The energy transition aims to expand the use of renewable energy technologies, while the new law forbids the construction of new nuclear power plants (SFOE, 2017). Hence, people who exhibit portfolio preferences similar to those seen in cluster 3 (new nuclear power) might show the most resistance towards the implementation of the new law. Although the magnitude of this group remains somewhat unclear, we believe that the preference for new nuclear power plants will not be widespread. Furthermore, the acceptance levels for nuclear power were found to be either lower (Rehdanz et al., 2017; Woo et al., 2017) or relatively stable (Siegrist and Visschers, 2013) in the post-Fukushima area after 2011. Our findings show the majority of respondents to favour renewable energy sources in their portfolios, which is in in accordance with the acceptance levels associated with renewables (Bronfman et al., 2012; Ertör-Akyaz1 et al., 2012; Greenberg and Truelove, 2011; Tampakis et al., 2013).

The way in which renewables are to be included in the Swiss electricity mix is not straightforward. The majority of people prefer the expansion of domestic renewables. However, one identified group prefers to combine renewables with natural gas, another with nuclear power while a third would prefer to import more renewable electricity instead. Hence, in terms of policy implementation, it is not only necessary to consider the type of energy technology that the public wishes to promote domestically, but also whether and with which other energy technologies the public prefers to combine them in a portfolio.

\subsection{Limitations}

Several limitations must be considered in relation to our study. First, the sample we analysed is not truly representative of the general Swiss population, being on average older and better educated. However, considering that we investigated a sample that could potentially be more homogenous, we find that their views regarding the best electricity mix for Switzerland are actually quite divergent. By extension, examining a more representative sample should hence involve even broader views. We must assume that the public as a stakeholder might hold even more diverse and possibly opposing views in terms of their electricity portfolio preferences. Regarding the finding that affect guides portfolio preferences, we deem the result valid, since the regression controls for age. 
Further, not all the variables that potentially influence portfolio choice were included in this study. However, it is important to recognise that they could potentially influence portfolio choice, since they have previously been shown to influence acceptance. For example, trust in responsible actors (DevineWright, 2012; Perlaviciute and Steg, 2014), the perceived procedural and distributive fairness (Tabi and Wüstenhagen, 2017; Visschers and Siegrist, 2012) have all been shown to influence acceptance. Additionally, people give weight to more contextual factors, such as the location and ownership of power plants (Parkhill et al., 2013; Tabi and Wüstenhagen, 2017). We did not take into account the specific siting of plants in relation to people's portfolio choices, since this corresponds to a mesoanalysis situated at the community level (Upham et al., 2015). However, siting does indeed matter with regards to acceptance, as has been found for power lines (Devine-Wright, 2012), nuclear power plants (Ansolabehere and Konisky, 2009) and renewables such as wind power (Larson and Krannich, 2016). Further, the influence of affect on portfolio choice might lessen if the respondents had additional information concerning their electricity portfolio choices. Affect is less strongly related to the level of acceptance when specific negative impacts (i.e. toxic waste) are mentioned (Sütterlin and Siegrist, 2017). We hence suggest that future research should provide both more time and further information on the consequences of people's portfolio choice. This could potentially stimulate more deliberate choices (Bessette et al., 2014; Bessette et al., 2016; Mayer et al., 2014) that rely less on affective evaluations. By so doing, we could obtain a better understanding of the role of affect in choice situations, where additional information is provided.

\section{Conclusion and policy implications}

Through this study, we gained knowledge about the drivers of electricity portfolio preferences under more realistic conditions when compared to previous investigations of public acceptance. We found strong evidence for an affective model. The feelings evoked by energy technologies are crucial in terms of driving people's preferences for the country's future electricity mix. Further, we observed that the examined sample, despite being more homogeneous in relation to both age and education than the general Swiss population, revealed opposing and possibly incompatible preferences as to what they 
considered the best electricity mix. The groups with distinctive portfolio preferences partly differed with regards to their concerns about climate change and the societal costs and environmental impacts of electricity production, which seem to play an additional role in people's choice of a combination of different energy sources. In relation to the implementation of the new energy law in Switzerland, the findings of this study suggest that positive affective reactions towards the energy technologies that are due to be expanded are necessary, albeit not necessarily sufficient, if public acceptance is to be achieved.

\section{Acknowledgements}

This research was financially supported by the Swiss National Science Foundation (project number 166098). We thank the anonymous reviewers for their comments on the previous version of the manuscript. 


\section{References}

Anshelm, J., Simon, H., 2016. Power production and environmental opinions - Environmentally motivated resistance to wind power in Sweden. Renewable and Sustainable Energy Reviews 57, 15451555 .

Ansolabehere, S., Konisky, D.M., 2009. Public attitudes toward construction of new power plants. Public Opinion Quarterly 73, 566-577.

Ansolabehere, S., Konisky, D.M., 2012. The American public's energy choice. Deadalus 141, 61 - 71. Ansolabehere, S., Konisky, D.M., 2014. Cheap and clean. How America thinks about energy in the age of global warming. The MIT Press, Cambridge, London.

Assouline, D., Mohajeri, N., Scartezzini, J.-L., 2017. Quantifying rooftop photovoltaic solar energy potential: A machine learning approach. Solar Energy 141, 278-296.

Backhaus, K., Erichson, B., Plinke, W., Weiber, R., 2003. Multivariate Analysemethoden [Multivariate Methods of Anlaysis]. Springer, Berlin.

Bessette, D.L., Arvai, J., 2018. Engaging attribute tradeoffs in clean energy portfolio development. Energy Policy 115, 221-229.

Bessette, D.L., Arvai, J., Campbell-Arvai, V., 2014. Decision support framework for developing regional energy strategies. Environmental Science \& Technology 48, 1401-1408.

Bessette, D.L., Campbell-Arvai, V., Arvai, J., 2016. Expanding the reach of participatory risk management: Testing an online decision-aiding framework for informing internally consistent choices. Risk Analysis 36, 992-1005.

Blumer, Y.B., Moser, C., Patt, A., Seidl, R., 2015. The precarious consensus on the importance of energy security: Contrasting views between Swiss energy users and experts. Renewable and Sustainable Energy Reviews 52, 927-936.

Breyer, B., 2015. Left-Right self-placement scale (ALLBUS / GGSS), The collection items and scales for the Social Sciences, CIS/ZIS.

Bronfman, N.C., Jiménez, R.B., Arévalo, P.C., Cifuentes, L.A., 2012. Understanding social acceptance of electricity generation sources. Energy Policy 46, 246-252.

Corner, A., Venables, D., Spence, A., Poortinga, W., Demski, C., Pidgeon, N., 2011. Nuclear power, climate change and energy security: Exploring British public attitudes. Energy Policy 39, 4823-4833.

CS, gfs.bern, 2017. Innenpolitischer Druck steigt. 41. Credit Suisse Sorgenbarometer [Domestic political pressure rises. 41st Credit Suisste Worry Barometer], Credit Suisse Worry Barometer.

Demski, C., Butler, C., Parkhill, K.A., Spence, A., Pidgeon, N.F., 2015. Public values for energy system change. Global Environmental Change 34, 59-69.

Demski, C., Poortinga, W., Pidgeon, N.F., 2014. Exploring public perceptions of energy security risks in the UK. Energy Policy 66, 369-378.

Demski, C., Spence, A., Pidgeon, N.F., 2017. Effects of exemplar scenarios on public preferences for energy futures using the my2050 scenario-building tool. Nature Energy 2, 17027.

Devine-Wright, P., 2012. Explaining "NIMBY" objections to a power line: The role of personal, place attachment and project-related factors. Environment and Behavior 45, 761-781.

Díaz, P., van Vliet, O.P.R., Patt, A., 2017. Do We Need Gas as a Bridging Fuel? A Case Study of the Electricity System of Switzerland. Energies 10, 861.

Eiser, J.R., Van der Pligt, J., 1979. Beliefs and values in the nuclear debate. Journal of Applied Social Psychology 9, 524-536.

Ertör-Akyazı, P., Adaman, F., Özkaynak, B., Zenginobuz, Ü., 2012. Citizens' preferences on nuclear and renewable energy sources: Evidence from Turkey. Energy Policy 47, 309-320.

FC, 2017. Volksabstimmung vom 21.05.2017, Energiegesetz (EnG) vom 30.09.2016 [popular vote of 21.05.217, Energy Act (EnA) from 30.09.2016], Federal Council, Swiss government, Bern. https://www.bk.admin.ch/ch/d/pore/va/20170521/index.html (accessed 1 April 2018).

Finucane, M., Alhakami, A., Slovic, P., Johnson, S.M., 2000. The affect heuristic in judgments of risks and benefits. Journal of Behavioral Decision Making 13, 1 - 17.

[dataset] FSO, 2017. Bildungsstand der Wohnbevölkerung nach Alter und Geschlecht, 1999-2016 [Education level of the resident population according to age and gender, 1999 - 2016], Federal Statistical Office, Bern. https://www.bfs.admin.ch/bfs/de/home/statistiken/bildung- 
September 2017).

Greenberg, M., 2009. Energy sources, public policy, and public preferences: Analysis of US national and site-specific data. Energy Policy 37, 3242-3249.

Greenberg, M., Truelove, H.B., 2011. Energy choices and risk beliefs: Is it just global warming and fear of a nuclear power plant accident? Risk Analysis 31, 819-831.

Huijts, N.M.A., Molin, E.J.E., Steg, L., 2012. Psychological factors influencing sustainable energy technology acceptance: A review-based comprehensive framework. Renewable and Sustainable Energy Reviews 16, 525-531.

Keller, C., Visschers, V.H.M., Siegrist, M., 2012. Affective imagery and acceptance of replacing nuclear power plants. Risk Analysis 32, 464-477.

Kienast, F., Huber, N., Hergert, R., Bolliger, J., Moran, L.S., Hersperger, A.M., 2017. Conflicts between decentralized renewable electricity production and landscape services - A spatially-explicit quantitative assessment for Switzerland. Renewable and Sustainable Energy Reviews 67, 397-407.

Larson, E.C., Krannich, R.S., 2016. “A Great Idea, Just Not Near Me!” Understanding Public Attitudes About Renewable Energy Facilities. Society \& Natural Resources 29, 1436-1451.

Lienert, P., Sütterlin, B., Siegrist, M., 2017. The influence of high-voltage power lines on the feelings evoked by different Swiss surroundings. Energy Research \& Social Science 23, 46-59.

Mayer, L.A., Bruine de Bruin, W., Morgan, M.G., 2014. Informed public choices for low-carbon electricity portfolios using a computer decision tool. Environmental Science \& Technology 48, 36403648 .

Noppers, E.H., Keizer, K., Bolderdijk, J.W., Steg, L., 2014. The adoption of sustainable innovations: Driven by symbolic and environmental motives. Global Environmental Change 25, 52-62.

Panos, E., Kannan, R., 2016. The role of domestic biomass in electricity, heat and grid balancing markets in Switzerland. Energy 112, 1120-1138.

Parkhill, K., Demski, C., Butler, C., Spence, A., Pidgeon, N., 2013. Transforming the UK energy system: Public values, attitudes and acceptability - synthesis report. UKERC, London.

Pattupara, R., Kannan, R., 2016. Alternative low-carbon electricity pathways in Switzerland and it's neighbouring countries under a nuclear phase-out scenario. Applied Energy 172, 152-168.

Perlaviciute, G., Steg, L., 2014. Contextual and psychological factors shaping evaluations and acceptability of energy alternatives: Integrated review and research agenda. Renewable and Sustainable Energy Reviews 35, 361-381.

Perlaviciute, G., Steg, L., 2015. The influence of values on evaluations of energy alternatives. Renewable Energy 77, 259-267.

Peters, E., Slovic, P., 1996. The role of affect and worldviews as orienting dispositions in the perception and acceptance of nuclear power. Journal of Applied Social Psychology 26, 1427-1453.

Pidgeon, N.F., Demski, C., Butler, C., Parkhill, K., Spence, A., 2014. Creating a national citizen engagement process for energy policy. Proceedings of the National Academy of Sciences of the United States of America 111, 13606-13613.

Pidgeon, N.F., Lorenzoni, I., Poortinga, W., 2008. Climate change or nuclear power-No thanks! A quantitative study of public perceptions and risk framing in Britain. Global Environmental Change 18, 69-85.

Rehdanz, K., Schröder, C., Narita, D., Okubo, T., 2017. Public preferences for alternative electricity mixes in post-Fukushima Japan. Energy Economics 65, 262-270.

Rudolf, M., Seidl, R., Moser, C., Krütli, P., Stauffacher, M., 2014. Public preference of electricity options before and after Fukushima. Journal of Integrative Environmental Sciences 11, 1-15.

SFOE, 2012. Wasserkraftpotenzial der Schweiz [Hydropower potential in Switzerland], Swiss Federal Office of Energy, Ittigen.

SFOE, 2013. Energieperspektiven 2050 - Zusammenfassung [Energy scenarios 2050 - summary], Swiss Federal Office of Energy, Ittigen.

SFOE, 2016. Schweizerische Elektrizitätsstatistik [Swiss Electricity statistic], Swiss Federal Office of Energy, Ittigen.

SFOE, 2017. Wichtigste Neuerungen im Energierecht ab 2018 [Main alterations in the Energy law starting 2018], Swiss Federal Office of Energy, Ittigen. 
Siegrist, M., Cousin, M.E., Kastenholz, H., Wiek, A., 2007. Public acceptance of nanotechnology foods and food packaging: the influence of affect and trust. Appetite 49, 459-466.

Siegrist, M., Visschers, V.H.M., 2013. Acceptance of nuclear power: The Fukushima effect. Energy Policy 59, 112-119.

Slovic, P., Finucane, M.L., Peters, E., MacGregor, D.G., 2004. Risk as Analysis and Risk as Feelings: Some Thoughts about Affect, Reason, Risk and Rationality. Risk Analysis 24, 311 - 322.

Slovic, P., Finucane, M.L., Peters, E., MacGregor, D.G., 2007. The affect heuristic. European Journal of Operational Research 177, 1333-1352.

Spence, A., Poortinga, W., Pidgeon, N.F., Lorenzoni, I., 2010. Public perceptions of energy choices: The influence of beliefs about climate change and the environment. Energy \& Environment 21, 385 407.

Stokes, L.C., Warshaw, C., 2017. Renewable energy policy design and framing influence public support in the United States. Nature Energy 2, 17107.

Stykow, P., 2007. Vergleich politischer Systeme [Comparison of political systems]. Wilhelm Fink / UTB, Paderborn.

Sütterlin, B., Siegrist, M., 2017. Public acceptance of renewable energy technologies from an abstract versus concrete perspective and the positive imagery of solar power. Energy Policy 106, 356-366.

Tabi, A., Wüstenhagen, R., 2017. Keep it local and fish-friendly: Social acceptance of hydropower projects in Switzerland. Renewable \& Sustainabe Energy Reviews 68, 763-773.

Tampakis, S., Tsantopoulos, G., Arabatzis, G., Rerras, I., 2013. Citizens' views on various forms of energy and their contribution to the environment. Renewable \& Sustainable Energy Reviews 20, 473482.

Tobler, C., Visschers, V.H.M., Siegrist, M., 2012. Consumers' knowledge about climate change. Climatic Change 114, 189-209.

Truelove, H.B., 2012. Energy source perceptions and policy support: Image associations, emotional evaluations, and cognitive beliefs. Energy Policy 45, 478-489.

Upham, P., Oltra, C., Boso, À., 2015. Towards a cross-paradigmatic framework of the social acceptance of energy systems. Energy Research \& Social Science 8, 100-112.

Vainio, A., Paloniemi, R., Varho, V., 2017. Weighing the Risks of Nuclear Energy and Climate Change: Trust in Different Information Sources, Perceived Risks, and Willingness to Pay for Alternatives to Nuclear Power. Risk Analysis 37, 557-569.

Visschers, V.H.M., Keller, C., Siegrist, M., 2011. Climate change benefits and energy supply benefits as determinants of acceptance of nuclear power stations: Investigating an explanatory model. Energy Policy 39, 3621-3629.

Visschers, V.H.M., Siegrist, M., 2012. Fair play in energy policy decisions: Procedural fairness, outcome fairness and acceptance of the decision to rebuild nuclear power plants. Energy Policy 46, 292-300.

Visschers, V.H.M., Siegrist, M., 2014. Find the differences and the similarities: Relating perceived benefits, perceived costs and protected values to acceptance of five energy technologies. Journal of Environmental Psychology 40, 117-130.

Visschers, V.H.M., Wallquist, L., 2013. Nuclear power before and after Fukushima: The relations between acceptance, ambivalence and knowledge. Journal of Environmental Psychology 36, 77-86.

Woo, J., Moon, H., Lee, J., Jang, J., 2017. Public attitudes toward the construction of new power plants in South Korea. Energy \& Environment 28, 499-517. 